\title{
CHRONIC EXPOSURE TO FLUOXETINE (PROZAC) CAUSES DEVELOPMENTAL DELAYS IN RANA PIPIENS LARVAE
}

\author{
Hannah R. Foster, $* \dagger$ G. Allen Burton, $\ddagger$ Niladri Basu, $§$ and Earl E. Werner $\|$ \\ $\dagger$ Ecology and Evolutionary Biology, University of Michigan, Ann Arbor, Michigan 48109, USA \\ $\ddagger$ School of Natural Resources and Environment and Cooperative Institute for Limnology and Ecosystems Research, \\ University of Michigan, Ann Arbor, Michigan 48109, USA \\ §Department of Environmental Health Sciences, University of Michigan, Ann Arbor, Michigan 48109, USA \\ ||Ecology and Evolutionary Biology, University of Michigan, Ann Arbor, Michigan 48109, USA
}

(Submitted 11 May 2010; Returned for Revision 14 June 2010; Accepted 11 August 2010)

\begin{abstract}
Selective serotonin reuptake inhibitors (SSRIs), such as fluoxetine, are among the many pharmaceuticals detected in aquatic ecosystems. Although the acute effects of SSRIs on select organisms have been reported, little is understood about the chronic effects of these drugs on amphibians, which are particularly sensitive to environmental pollutants. Serotonin plays important roles in many physiological functions, including a wide array of developmental processes. Exposure to SSRIs during development may cause developmental complications in a variety of organisms, but little is known about the degree of exposure necessary to cause deleterious effects. Here, we sought to gain a better understanding of the effects of SSRIs on amphibian development by use of a combined laboratory and outdoor mesocosm study. Tadpoles in a laboratory setting were exposed to a low $(0.029 \mu \mathrm{g} / \mathrm{L})$ and a high $(0.29 \mu \mathrm{g} / \mathrm{L})$ concentration of the common SSRI fluoxetine from stages 21 and 22 through completion of metamorphosis. Tadpoles in outdoor mesocosms were exposed to fluoxetine concentrations ranging from 0.1 to $0.3 \mu \mathrm{g} / \mathrm{L}$. Exposed tadpoles in the laboratory showed delayed development compared with controls when stage was assessed throughout the experiment. Control tadpoles also gained weight faster than treatment tadpoles, which may be explained by reduced food intake. Mesocosm tadpoles exhibited similar trends, but no significant differences were detected. These results indicate that ecologically relevant levels of fluoxetine may cause developmental delays in amphibians. Environ. Toxicol. Chem. 2010;29:2845-2850. (C) 2010 SETAC
\end{abstract}

Keywords-Pharmaceuticals Toxicity Selective serotonin reuptake inhibitor Amphibian Environment

\section{INTRODUCTION}

Trace quantities of human and veterinary pharmaceuticals have been detected in diverse water sources, such as surface waters, groundwater, seawater, and even drinking water [1-3]. Most human pharmaceuticals enter such aquatic systems through wastewater treatment plants (WWTPs) primarily due to human defecation of pharmaceuticals and their metabolites after use [4,5]. Although measured concentrations of these chemicals in receiving waters are small (i.e., sub part per billion) [5], growing evidence indicates that such low levels may be affecting aquatic organisms, that synergistic interactions occur, and that levels are increasing [4]. Accordingly, pharmaceuticals in waterways are considered a class of environmental contaminant of global importance [1]. Given that a majority of ecotoxicological studies on pharmaceuticals have focused on their acute toxicity [1,6], little is known about their impacts on organisms and ecosystems after chronic exposures to real-world levels $[1,6]$.

Selective serotonin reuptake inhibitors (SSRIs) are among the most commonly prescribed drugs in the United States, with fluoxetine and sertraline in the top 20 most frequently prescribed drugs in 2007 (http://drugtopics.modernmedicine.com/ drugtopics/Top200Drugs/ArticleStandard/article/detail/491194). At least four drugs of this class and their active metabolites have been detected in WWTP raw wastewater at individual levels as high as $0.223 \mu \mathrm{g} / \mathrm{L}[2,3,7,8]$. Fluoxetine has been

* To whom correspondence may be addressed (fosterh@umich.edu).

Published online 9 September 2010 in Wiley Online Library (wileyonlinelibrary.com). found in sewage treatment plant effluents and surface waters at concentrations as high as $0.099 \mu \mathrm{g} / \mathrm{L}$ [9]. In addition, evidence has been noted of bioaccumulation, since fluoxetine, citalopram, sertraline, and their metabolites have been measured in the tissues of fish living in effluent-dominated streams [3,10].

In humans, SSRIs are used primarily to treat chronic depression and compulsive disorders by blocking the reuptake of serotonin from the presynaptic nerve cleft [6]. Serotonin is conserved across organisms, and in addition to its neurochemical role, with subsequent effects on mood and behavior [11], it mediates many other physiological processes in every class of organisms [12-14]. For example, serotonin plays a crucial role in immune function, steroid concentrations, and sexual function. Serotonin is also critical during key developmental processes in every organism studied thus far [6,13-15], and exposure to SSRIs during development is believed to cause deformities or other developmental complications in a wide array of organisms, including sea urchins, birds, mice, and even humans $[13,14,16-18]$. However, little is known about the dose and duration of exposure necessary to cause deleterious effects in developing embryos and whether such early-life exposures result in later-life effects.

Many aquatic organisms are currently threatened or endangered, but recent drastic declines in amphibian populations have led to great concern for their preservation, and research has shown that amphibians may be particularly susceptible to environmental stressors. Most amphibians live in water throughout their egg and larval stages, making them exceptionally vulnerable to aquatic contaminants during this critical time of development. Furthermore, their shell-less eggs and permeable skin easily allow the absorption of substances found 
in their aquatic habitat $[19,20]$. Thus, aquatic pollutants may be a contributor to global amphibian declines [20]. Although pharmaceuticals may not be a major contributor to amphibian declines because pharmaceutical contamination is limited to aquatic ecosystems near WWTPs [1], a better understanding of these contaminants still may aid in the effort to preserve amphibians as human populations, pharmaceutical use, and the prevalence of WWTPs increase worldwide.

In the present study, we sought to gain a more complete understanding of the effects of SSRIs on amphibian development after chronic exposures to relevant levels. To accomplish this, frogs (Rana pipiens) were exposed to low levels of SSRIs from stages 21 to 22 until the completion of metamorphosis both in the laboratory and in a mesocosm study. Because serotonin is critical to vertebrate craniofacial development, and changes in serotonin levels in developing embryos have been linked to skeletal deformities, we hypothesized that frogs raised in water with low levels of fluoxetine will exhibit an increase in developmental malformations. In addition, serotonin is thought to influence cell proliferation, as well as appetite and other behaviors, so we also expected to observe developmental delays and behavioral abnormalities.

\section{METHODS}

\section{Collection of frogs}

All procedures were approved by the University Committee for the Use and Care of Animals at the University of Michigan. For both the laboratory and mesocosm study, a total of approximately 1,500 Rana pipiens stage 21 and 22 larvae (according to the Gosner staging system, which assigns a stage, 1 to 46 , to frog larvae from egg to completion of metamorphosis, based on morphological developments [21]; heretofore stage) were collected from a small vernal pond in Livingston County, Michigan, USA, from at least two different egg masses on May 1, 2009. Although the history of contamination of this pond is unknown, it is likely not contaminated by pharmaceuticals because it is not in the vicinity of a WWTP.

\section{Chemical}

Fluoxetine hydrochloride (Toronto Research Chemicals) was dissolved in dechlorinated city water to achieve a stock solutions of $1 \mathrm{mg} / \mathrm{L}$. Stock solutions were refrigerated at $5^{\circ} \mathrm{C}$ and renewed every two to three weeks. The resulting concentration of fluoxetine in each treatment tank was verified by the Worsfold Water Quality Centre (Trent University, Peterborough, ON, Canada), using liquid chromatography-mass spectrometry as described in a previous article [22]. For this analysis, nine grab samples were taken from the laboratory and mesocosm experiments on August 10, 2009. Samples were taken from the laboratory experiments as follows: a composite of the three control tubs after water changing, one composite of the three high treatment tubs before and one after water changing, and one sample from each of the three low treatment tubs after water changing. For the mesocosm experiments, a composite of control water and a composite of the treated water before and after the spike were taken.

\section{Laboratory experiment}

Housing and care. Nine plastic 5.7-L Sterilite ${ }^{\circledR}$ plastic boxes were filled with $4 \mathrm{~L}$ of dechlorinated city water (pH 7.05). Boxes were kept at $23^{\circ} \mathrm{C}$ on a 16:8 light:dark schedule. To each box, 20 stage 21 to 22 tadpoles were arbitrarily added on May 8, 2010 (day 0). Tadpoles were fed an ad libitum diet of rabbit chow and TetraMin ${ }^{\circledR}$ tropical fish flakes in a 10:1 ratio every 2 to $3 \mathrm{~d}$. Boxes were randomly selected to contain water with no fluoxetine (control), a low, environmentally relevant treatment $(<0.1 \mu \mathrm{g} / \mathrm{L})$, and a high treatment $(<1.0 \mu \mathrm{g} / \mathrm{L})$, resulting in three replicates for each treatment and 20 tadpoles per replicate. Water was changed (100\% static renewal) every 3 to $4 \mathrm{~d}$.

Monitoring stage and weight. The stage of each individual tadpole was assessed and recorded on day 33, day 40, and day 50. Weight was recorded on 20 different days from day 5 until day 45 by weighing the tadpoles of each tub collectively to obtain an average weight. We stopped weighing the animals collectively on day 45 because some of the tadpoles were beginning to metamorphose, at which point tadpoles lose weight until completion of metamorphosis. When forelimbs were nearly fully developed and tail resorption was beginning, the tadpole was removed from its box and placed in a slightly sloped container containing $100 \mathrm{ml}$ water with, depending on the original treatment to which the tadpole belonged, no fluoxetine or the high or low concentration of fluoxetine. All tadpoles from the same treatment were housed together once they reached forelimb bud development, but at no point did the number of tadpoles in the sloped boxes exceed 5, and we kept track of the replicates from which each of the tadpoles came. The progress of each tadpole was tracked from forelimb bud development until the completion of metamorphosis or death. On completion of metamorphosis (complete tail resorption) or death, the date was recorded. Tadpole weight was recorded when a tadpole completed metamorphosis. Metamorphosed individuals were anesthetized by using tricaine methanesulfonate and killed by quick-freezing on dry ice.

Swimming ability test. On day 42, 12 tadpoles from each treatment were randomly selected to participate in a swimming speed assessment (to control for weight and stage, however, selection was limited to tadpoles between the stages of 25 and 31) based on methods previously described by Chen et al. [23]. A 1-m racetrack was created out of plastic gutter material. A tadpole was placed in a $6-\mathrm{cm}$ section blocked off by a piece of plastic in front of the start of the 1-m track and was allowed to acclimate for $30 \mathrm{~s}$. At this point, the plastic was lifted. To achieve maximum swimming speed, the tadpole was chased down the track with a thin strip of plastic ( $1 \mathrm{~cm}$ in width). The person chasing the tadpoles was blind to the treatment from which each tadpole came. The time it took for a tadpole to reach the end of the 1-m track, while being chased, was recorded and converted to speed in centimeters per second. Each tadpole was tested only once.

Feeding time. Individual tadpoles (12 randomly chosen per treatment group) were monitored on day 25 for differences in time spent feeding. Because tracking a single tadpole in its tub with many other tadpoles is quite difficult, a tadpole was placed in a separate $250-\mathrm{ml}$ beaker of water with a fresh pellet of rabbit chow and allowed to acclimate for $5 \mathrm{~min}$. Time spent feeding during the next 5 min was recorded.

\section{Mesocosm experiment}

To evaluate whether fluoxetine would similarly affect tadpoles raised in a more natural setting, we also set up a mesocosm experiment with a control and an exposed group on May 1, 2010 (Day 0-M; 'M', denotes mesocosm). Tadpoles (30 per tub) were housed in eight 64-L plastic storage bins filled with pond water and sediment in the Saginaw Forest Preserve (Ann Arbor, MI, USA). Algae was collected from the local pond and added to the tubs as food for the tadpoles. Four of the tubs were treated 
with fluoxetine, and the other four served as untreated controls. Because previous studies had reported adsorption of fluoxetine into the soil in outdoor water systems [24], treated tubs were spiked twice per week with $0.05 \mathrm{~g}$ fluoxetine, thus resulting in a nominal concentration of less than $1 \mu \mathrm{g} / \mathrm{L}$. Tubs were covered with screen to avoid invasion by predators and monitored every 3 to $4 \mathrm{~d}$. On day $123-\mathrm{M}$, as the first of the tadpoles were developing forelimbs, the weight and stage of each tadpole was recorded.

\section{Statistical analysis}

For the laboratory study, a repeated measures analysis of variance was used to assess differences in weight among treatments over the course of $20 \mathrm{~d}$ from day 5 until day 45, and a Friedman test was used to determine differences in stage among treatments on day 33 , day 40 , and day 50. Because post-hoc comparisons are not possible for nonparametric tests, a Wilcoxon test with Bonferroni adjustments was used to assess specific differences between individual treatments. Variables measured only at the termination of the experiment were examined using one-way analysis of variance when the assumptions of normality and equal variance (Levene's homogeneity of variance) were met. Time to metamorphosis, weight on completion, and swimming speed met the assumptions of analysis of variance, and post-hoc comparisons were made using Tukey's honestly significant difference test. Feeding activity exhibited unequal variances, and treatments were compared by using a Kruskal-Wallis nonparametric test. For the mesocosm test, an independent samples $t$ test was applied to test for significant differences in stage and weight of tadpoles.

\section{RESULTS}

\section{Liquid chromatography-mass spectrometry analysis}

In the composite sample of water from the control tubs used in the laboratory study, a concentration of $0.005 \mu \mathrm{g} / \mathrm{L}$ fluoxetine was measured (limit of quantitation $=0.003$ ). The measured fluoxetine concentration of the low treatment $(<0.1 \mu \mathrm{g} / \mathrm{L})$ was $0.029 \mu \mathrm{g} / \mathrm{L}( \pm 0.005 \mu \mathrm{g} / \mathrm{L})$, and the concentration of the composite for the high treatment $(<1.0 \mu \mathrm{g} / \mathrm{L})$ was $0.08 \mu \mathrm{g} / \mathrm{L}$ before water changing and $0.29 \mu \mathrm{g} / \mathrm{L}$ after water changing. The concentration of fluoxetine in the mesocosm experiment control tubs was less than the limit of quantitation $(0.003 \mu \mathrm{g} / \mathrm{L})$, whereas the fluoxetine concentration measured in the experimental tubs ranged from 0.110 to $0.310 \mu \mathrm{g} / \mathrm{L}$, because of the spiking of the tubs twice per week.

\section{Laboratory experiment}

Survivorship and malformations. No malformations were observed in any of the tadpoles. No dose-dependent changes in survivorship were seen among treatments in either the laboratory experiment or the mesocosm experiment.

Stages, weights, and time to metamorphosis. When stage was assessed on day 33, day 40, and day 50, control tadpoles were significantly further developed than both low$(Z=-2.666$; corrected $p=0.024)$ and high-treatment tadpoles $(Z=-2.666$; corrected $p=0.024$; Fig. 1$)$. No difference was seen in stage between the medium and high fluoxetine-treated tadpoles.

Results for tadpole weight exhibited a similar trend ( $F_{2,6}=11.744, p=0.008$; Fig. 2). Tadpoles in the control group gained weight significantly faster than those in the high

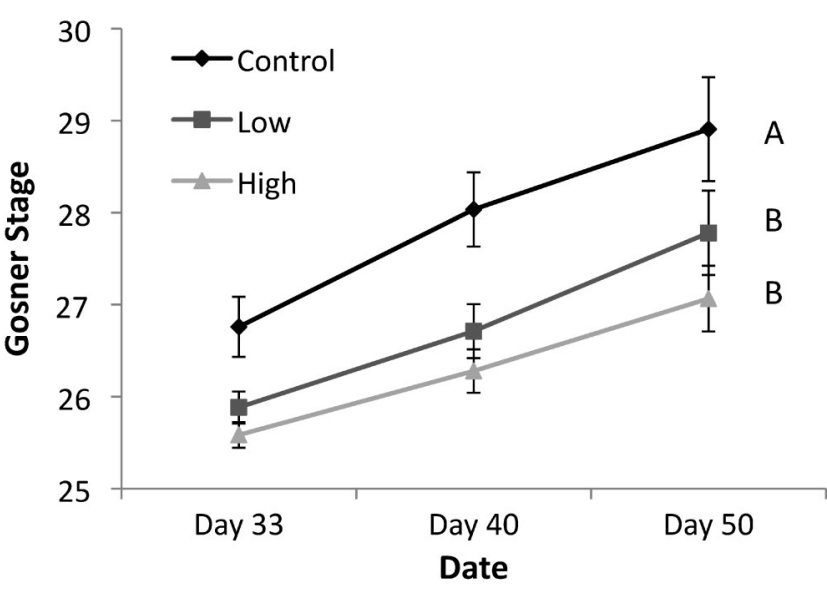

Fig. 1. Mean stage ( \pm standard error) of tadpoles on day 33, day 40, and day 50 ( $n=3$ per treatment group per day). Capital letters denote significant differences $(p<0.05)$.

treatment group ( $p=0.007)$ and faster than those in the low treatment groups, although the difference was only marginally significant in this case $(p=0.064)$. Weight in the control group had a slope (g/d) $10 \%$ greater than that of those exposed to low concentrations of fluoxetine and $19 \%$ greater than high-treatment tadpoles between day 5 and day 45 (Fig. 2). Weight at forelimb bud development was not significantly different among treatments $\left(F_{2,6}=1.772, p=0.267\right)$, but the trend was the same, with control tadpoles weighing approximately $25 \%$ more than low- and high-treatment tadpoles, which were similar in weight. At completion of metamorphosis, treatments did exhibit nearly significant differences in weight; this time, however, between high-treatment tadpoles, weighing $0.81 \mathrm{~g}$, and low-treatment tadpoles, weighing 0.61 grams ( $F_{2,6}=4.630 ; p=0.061$; Fig. 3A). No significant differences were found between the weight of high-treatment tadpoles and that of control treatment tadpoles $(p=0.795)$.

For time to completion of metamorphosis, although trends were observed, these were not of statistical significance ( $\left.F_{2,6}=1.49, p=0.298\right)$. Control tadpoles averaged completion of metamorphosis in $93 \mathrm{~d}( \pm 12 \mathrm{~d})$, completing metamorphosis three weeks in advance of low-treatment tadpoles $(115 \pm 9 \mathrm{~d}$;

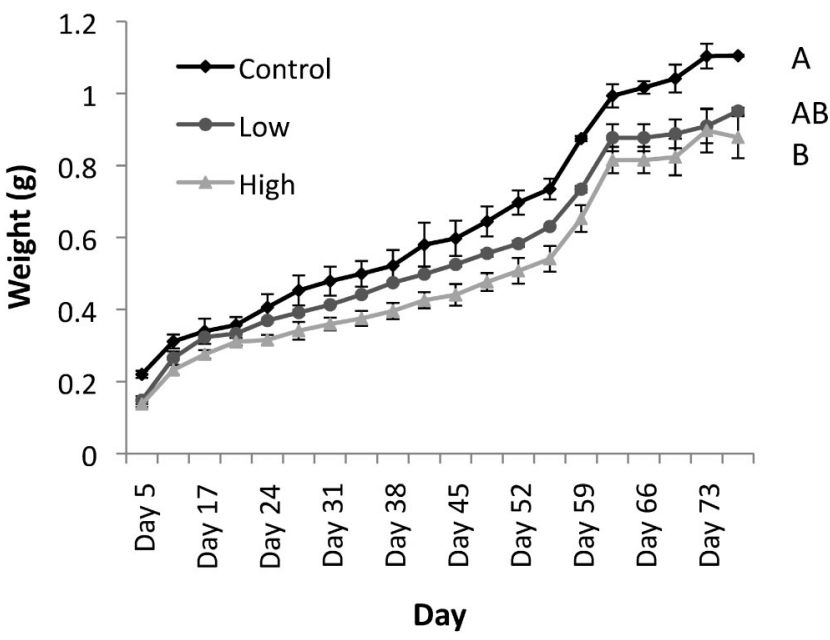

Fig. 2. Mean weight ( \pm standard error) of tadpoles on $20 \mathrm{~d}$ between day 5 and day 45 ( $n=3$ per treatment group per day). Capital letters denote significant differences $(p<0.05)$. 


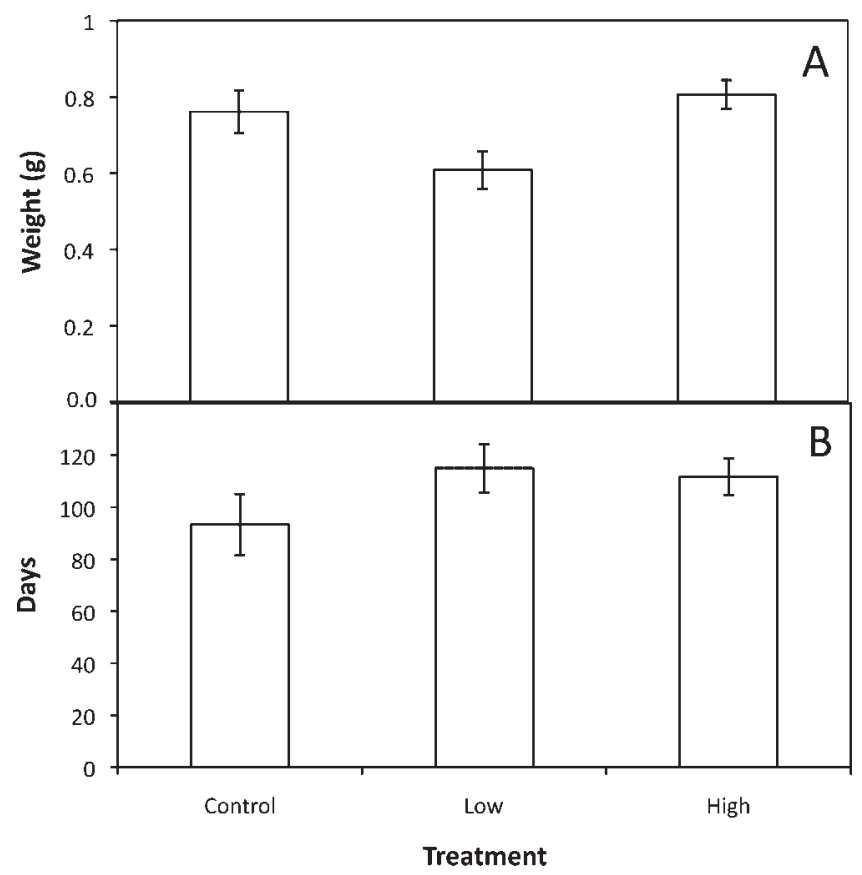

Fig. 3. (A) Mean weight ( \pm standard error) of tadpoles on completion of metamorphosis ( $n=3$ per treatment group). (B) Mean time to metamorphosis (days; \pm standard error) of tadpoles ( $n=3$ per treatment group).

$p=0.315)$ and $18 \mathrm{~d}$ before high-treatment tadpoles $(111 \pm 7 \mathrm{~d}$; $p=0.418$; Fig. 3B).

\section{Behavioral tests}

For tests on swimming speed, no fluoxetine-dependent differences were found. For the feeding test, no significant differences were observed among treatments. However, a nonsignificant trend was observed with control tadpoles spending, on average, more time feeding than the low- and high-treatment tadpoles (Fig. 4).

\section{Mesocosm experiment}

Although the trends for weight and stage in the mesocosm experiment were similar to those observed in the laboratory experiment, surviving control tadpoles on day 123-M were not significantly further developed nor significantly heavier than treated animals (Fig. 5).

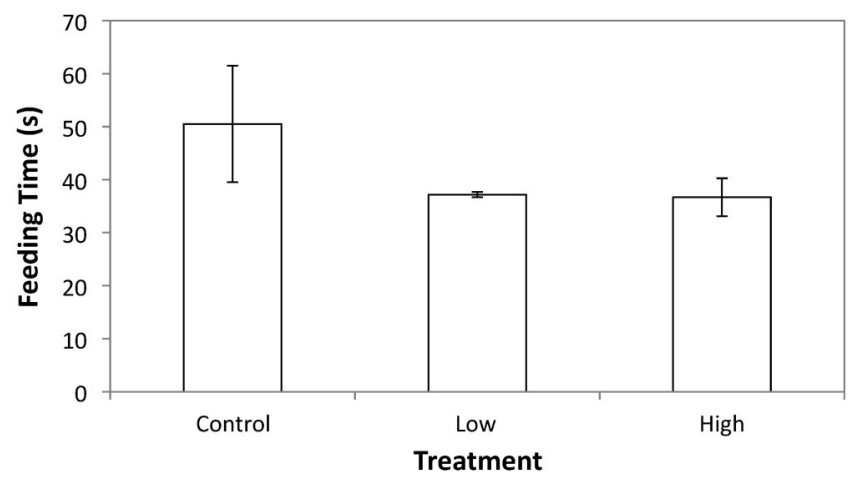

Fig. 4. Mean time spent feeding ( \pm standard error) during $5 \mathrm{~min}$ of observation ( $n=3$ per treatment group).

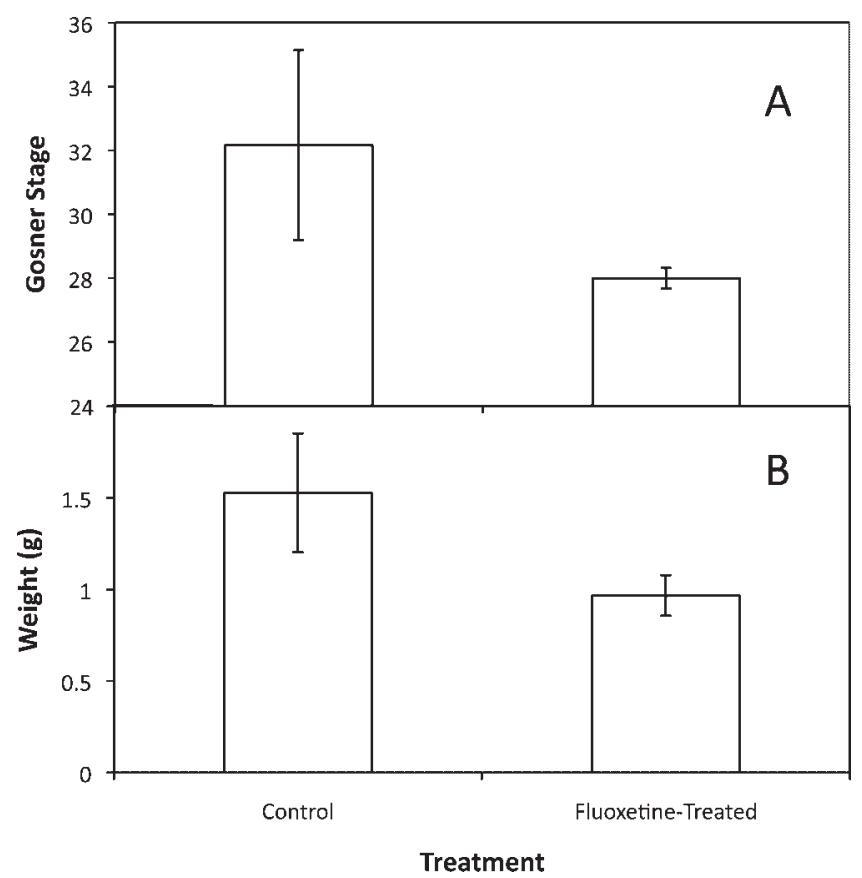

Fig. 5. (A) Mean stage ( \pm standard error) of tadpoles in mesocosm experiment on day 123-M ( $n=4$ per treatment group). (B) Mean weight ( \pm standard error) of tadpoles in mesocosm experiment on day 123-M.

\section{DISCUSSION}

Aquatic contaminants can have dramatic effects on the exposed organisms, resulting in deformities, illness, increased stress, or death, among other things. Although differences in behavior, malformations, and mortality were not detected, the results of this study indicate that chronic exposure to environmentally relevant concentrations of the aquatic contaminant fluoxetine may cause developmental delays and decreased growth in $R$. pipiens tadpoles. Retarded growth and development can be detrimental to individual amphibians as well as amphibian populations at large, and in severe cases, may cause local population declines [25].

Experimental concentrations of fluoxetine for the low treatment were determined to be well within the range of environmentally relevant concentrations (0.012-0.099 $\mu \mathrm{g} / \mathrm{L})$ [9], whereas the concentration of fluoxetine in the high treatment was approximately three times the highest recorded concentration in the environment. When samples were taken at the end of the summer, fluoxetine was discovered in water from the controls at a level of $0.005 \mu \mathrm{g} / \mathrm{L}$. This indicates that there may have been some contamination in the collection process, or the control tadpoles may have been exposed to an extremely low dosage of fluoxetine at some time during the experiment. We do not believe this exposure influenced the outcome of our experiment because exposure time was probably limited to a short period, and the measured level approached the analytical limit of detection.

No significant differences in malformations or overall mortality were observed. These results confirm the findings made by Conners et al. [26] in Xenopus laevis tadpoles that were exposed for $70 \mathrm{~d}$ to fluoxetine $(0.1,1,10 \mu \mathrm{g} / \mathrm{L})$. Here, tadpoles exposed to fluoxetine at both high and low concentrations exhibited delays in development in laboratory experiments. Tadpoles in the control group also gained weight faster than 
low- and high-treatment groups between day 5 and day 45. Of note, high-treatment tadpoles appeared to lose less weight from forelimb bud development to completion of metamorphosis, allowing them to surpass low-treatment tadpoles in weight by the time they completed metamorphosis. Although the mechanism behind this is unclear, Conners et al. [26] found an acceleration in developmental rate closer to metamorphosis for tadpoles treated with sertraline, another SSRI. Additionally, Conners et al. [26] did not observe reduced weight in tadpoles before metamorphosis, but they did find reduced weight in tadpoles exposed to higher concentrations of fluoxetine $(10 \mu \mathrm{g} / \mathrm{L})$ on completion of metamorphosis.

In mesocosm experiments, similar trends were observed, but the differences were not of statistical significance. However, because of the propensity for variability in outdoor mesocosms and the small sample size, this is likely attributable to a lack of statistical power. The combined results from the laboratory and mesocosm studies suggest that chronic exposures to ecologically relevant levels of fluoxetine may delay amphibian development and impact weight gain.

The observation of fluoxetine-associated delays in development and decreased weight may be caused by a number of factors. Most notably, SSRIs are known anorexigenics [27], acting at the level of food intake [28], so exposure to fluoxetine may reduce appetite and, consequently, food intake in tadpoles. Reduced food intake in turn could result in delayed development and reduced weight. Here, food intake was measured in a subset of animals, and although a trend of control tadpoles eating more than exposed tadpoles was seen, this was not statistically significant. Conners et al. [26] observed decreased food intake in tadpoles treated with fluoxetine as well, coming to similar conclusions that tadpole exposure to SSRIs may result in decreased food intake, thereby delaying development. Further study with increased sample sizes and rigorous and more regular measures of food intake might elucidate these results.

Decreased weight in amphibian larvae, as seen in this experiment, is hypothesized to be deleterious to amphibian populations for many reasons. Numerous studies have reported patterns in size-specific predation in larval anurans, with increased risk of predation for smaller tadpoles [29,30]. This size-specific predation is observed in part because faster-growing tadpoles quickly become too large for the gape size of certain predators $[25,31]$. Moreover, weight is generally correlated with swimming speed [32,33], so, although no differences in swimming speed among treatments were found in this study because we controlled for size, fluoxetine may indirectly impact swimming speed by decreasing larval size. Therefore, exposed tadpoles may be less capable of escaping predation because of decreased swimming speed caused by retarded development.

In the current study, significant differences in time to metamorphosis among treatments were not detected, but trends similar to those throughout metamorphosis were observed. We believe that the nonsignificance of our results in this case is probably attributable to a lack of statistical power because we only had three replicates per treatment. Time to metamorphosis is critical for larval survival because larvae of amphibian species such as $R$. pipiens, which normally complete metamorphosis in the first summer after egg laying, will likely die if they do not fully metamorphose during that summer and are forced to overwinter [25]. Additionally, because many amphibians lay their eggs in temporary ponds to avoid predation by fish, failure to complete metamorphosis before the pond dries could result in increased crowding and competition or desiccation [34].
This study was limited in that we were not able to begin the study with ova, so many of the key morphogenic events were completed before commencement of the study. Serotonin is critical in very early development, and changes in the level of serotonin may be particularly detrimental during cleavage, gastrulation, neurulation, cardiac and craniofacial morphogenesis, and the establishment of normal left-right asymmetry $[16,35,36]$. Therefore, exposure during all stages of development, especially early development, may uncover more serious consequences of chronic fluoxetine exposure.

The results of this study indicate that even environmentally relevant concentrations of fluoxetine may delay the development of tadpoles, thereby putting tadpoles at greater risk of desiccation and overcrowding as temporal ponds dry, as well as size-specific predation. Although not considered in this study, added stressors, such as disease and habitat alterations, may act synergistically with fluoxetine, as with other toxicants, to amplify the effects of fluoxetine or cause additional unforeseen consequences [25]. Moreover, considering the synergistic effects of animal exposure to multiple drugs is important, since fluoxetine is frequently found in company with other SSRIs, as well as many other classes of drugs and contaminants [1-4]. In fact, at least two studies have found fluoxetine, when combined with other drugs or toxins, to have both lethal and sublethal effects on phytoplankton and Daphnia magna [37,38]. Future studies involving amphibian exposure to pharmaceuticals and other aquatic contaminants could help illuminate the causes of some of the massive declines in amphibian populations and point us towards ways of averting further extinctions.

Acknowledgement-Financial support was provided by the Frontiers Master's Program at the University of Michigan and the Peter Olaus Okkelberg Fellowship funds. We would like to thank Mark Hunter, the Werner laboratory, and the Burton laboratory (especially Jessica Middlemis Maher, David Costello, Miling Li, and Laura Palombi) for their assistance, encouragement, and scientific input.

\section{REFERENCES}

1. Fent K, Weston AA, Caminada D. 2006. Ecotoxicology of human pharmaceuticals. Aquat Toxicol 76:122-159.

2. Kolpin DW, Furlong ET, Meyer MT, Thurman EM, Zaugg SD, Barber LB, Buxton HT. 2002. Pharmaceuticals, hormones, and other organic wastewater contaminants in US streams, 1999-2000: A national reconnaissance. Environ Sci Technol 36:1202-1211.

3. Metcalfe CD, Chu S, Judt C, Li H, Oakes KD, Servos MR, Andrews DM 2010. Antidepressants and their metabolites in municipal wastewater and downstream exposure in an urban watershed. Environ Toxicol Chem 29:79-89.

4. Daughton CG. 2004. Non-regulated water contaminants: emerging research. Environmental Impact Assessment Review 24:711-732.

5. Lam MW, Young CJ, Brain RA, Johnson DJ, Hanson MA, Wilson CJ, Richards SM, Solomon KR, Mabury SA. 2004. Aquatic persistence of eight pharmaceuticals in a microcosm study. Environ Toxicol Chem 23:1431-1440.

6. Brooks BW, Foran CM, Richards SM, Weston J, Turner PK, Stanley JK, Solomon KR, Slattery M, La Point TW. 2003. Aquatic ecotoxicology of fluoxetine. Toxicol Lett 142:169-183.

7. Schultz MM, Furlong ET. 2008. Trace analysis of antidepressant pharmaceuticals and their select degradates in aquatic matrixes by LC/ ESI/MS/MS. Anal Chem 80:1756-1762.

8. Schultz MM, Furglon ET, Kolpin DW, Werner SL, Schoenfuss HL, Barber LB, Blazer VS, Norris DO, Vajda AM. 2010. Antidepressent pharmaceuticals in two US effluent-impacted streams: occurrence and fate in water and sediment, and selective uptake in fish neural tissue. Environ Sci Technol 44:1918-1925.

9. Metcalfe CD, Miao XS, Koenig BG, Struger J. 2003. Distribution of acidic and neutral drugs in surface waters near sewage treatment plants in the lower Great Lakes, Canada. Environm Toxicol Chem 22:2881-2889.

10. Ramirez AJ, Brain RA, Usenko S, Mottaleb MA, O’Donnell JG, Stahl LL, Wathen JB, Snyder BD, Pitt JL, Perez-Hurtado P, Dobbins LL, Brooks BW, Chambliss CK. 2009. Occurrence of pharmaceuticals and 
personal care products in fish: Results of a national pilot study in the United States. Environ Toxicol Chem 28:2587-2597.

11. Ten Eyck GR. 2008. Serotonin modulates vocalizations and territorial behavior in an amphibian. Behav Brain Res 193:144-147.

12. Adayev T, Ranasinghe B, Banerjee P. 2005. Transmembrane signaling in the brain by serotonin, a key regulator of physiology and emotion. Biosci Rep 25:363-385.

13. Levin M, Buznikov GA, Lauder JM. 2006. Of minds and embryos: Left-right asymmetry and the serotonergic controls of pre-neural morphogenesis. Dev Neurosci 28:171-185.

14. Moiseiwitsch JRD. 2000. The role of serotonin and neurotransmitters during craniofacial development. Crit Rev Oral Biol Med 11:230-239.

15. Buznikov GA, Peterson RE, Nikitina LA, Bezuglov VV, Lauder JM 2005. The pre-nervous serotonergic system of developing sea urchin embryos and larvae: Pharmacologic and immunocytochemical evidence. Neurochem Res 30:825-837.

16. Lauder JM. 1993. Neurotransmitters as growth regulatory signals: Role of receptors and 2nd messengers. Trends Neurosci 16:233-240.

17. Buznikov GA, Lambert HW, Lauder JJ. 2001. Serotonin and serotoninlike substances as regulators of early embryogenesis and morphogenesis. Cell Tissue Res 305:177-186.

18. Oberlander TF, Warburton W, Misri S, Aghajanian J, Hertzman C. 2006. Neonatal outcomes after prenatal exposure to selective serotonin reuptake inhibitor antidepressants and maternal depression using population-based linked health data. Arch Gen Psychiatry 63:898-906.

19. Jjemba PK. 2008. Pharma-Ecology: The Occurrence and Fate of Pharmaceuticals and Personal Care Products in the Environment. Wiley, Hoboken, NJ, USA.

20. Blaustein AR, Johnson PT. 2003. The complexity of deformed amphibians. Frontiers in Ecology and the Environment 1:87-94.

21. Gosner KL. 1960. A simplified table for staging anuran embryos and larvae with notes on identification. Herpetologica 16:183-190.

22. Zhao XM, Metcalfe CD. 2008. Characterizing and compensating for matrix effects using atmospheric pressure chemical ionization liquid chromatography: Tandem mass spectrometry: Analysis of neutral pharmaceuticals in municipal wastewater. Anal Chem 80:2010-2017.

23. Chen TH, Gross JA, Karasov WH. 2006. Sublethal effects of lead on northern leopard frog (Rana pipiens) tadpoles. Environ Toxicol Chem 25:1383-1389.
24. Kwon JW, Armbrust KL. 2006. Laboratory persistence and fate of fluoxetine in aquatic environments. Environ Toxicol Chem 25:25612568.

25. Carey C, Bryant CJ. 1995. Possible interrelations among environmental toxicants, amphibian development, and decline of amphibian populations. Environ Health Perspect 103:13-17.

26. Conners DE, Rogers ED, Armbrust KL, Kwon JW, Black MC. 2009 Growth and development of tadpoles (Xenopus laevis) exposed to selective serotonin reuptake inhibitors, fluoxetine and sertraline, throughout metamorphosis. Environ Toxicol Chem 28:2671-2676.

27. Halford JCG, Blundell JE. 2000. Separate systems for serotonin and leptin in appetite control. Ann Med 32:222-232.

28. Simansky KJ. 1996. Serotonergic control of the organization of feeding and satiety. Behav Brain Res 73:37-42.

29. Brodie ED, Formanowicz DR. 1983. Prey size preference of predators Differential vulnerability of larval anurans. Herpetologica 39:67-75.

30. Travis J, Keen WH, Juilianna J. 1985. The role of relative body size in a predator-prey relationship between dragonfly naiads and larval anuralns. Oikos 45:59-65.

31. Wilbur HM. 1980. Complex life-cycles. Annu Rev Ecol Syst 11:67-93.

32. Eidietis L. 2005. Size-related performance variation in the wood frog (Rana sylvatica) tadpole tactile-stimulated startle response. Canadian Journal of Zoology-Revue Canadienne De Zoologie 83:1117-1127.

33. Arendt JD. 2009. Influence of sprint speed and body size on predator avoidance in New Mexican spadefoot toads (Spea multiplicata). Oecologia 159:455-461.

34. Griffiths RA. 1997. Temporary ponds as amphibian habitats. Aquatic Conservation-Marine and Freshwater Ecosystems 7:119-126.

35. Fukumoto T, Kema IP, Levin M. 2005. Serotonin signaling is a very early step in patterning of the left-right axis in chick and frog embryos. Curr Biol 15:794-803.

36. Gustafson T, Toneby M. 1970. On role of serotonin and acetylcholine in sea urchin morphogenesis. Exp Cell Res 62:102-117.

37. Flaherty CM, Dodson SI. 2005. Effects of pharmaceuticals on Daphnia survival, growth, and reproduction. Chemosphere 61:200- 207.

38. Brooks BW, Turner PK, Stanley JK, Weston JJ, Glidewell EA, Foran CM, Slattery M, La Point TW, Huggett DB. 2003. Waterborne and sediment toxicity of fluoxetine to select organisms. Chemosphere 52:135-142. 